\title{
ACETABULAR COVER IN CONGENITAL DISLOCATION OF
}

\section{THE HIP}

\author{
S. OGATA, H. MORIYA, K. TSUCHIYA, T. AKITA, M. KAMEGAYA, M. SOMEYA
}

From Chiba University, Japan

\begin{abstract}
The exact measurement of femoral head cover is essential for an assessment of reduction of congenital dislocation of the hip. We have compared standard anteroposterior radiographs with computerised tomograms and thereby classified the shape of the acetabular roof into four types.

We found that the $\mathrm{CE}$ angle of Wiberg is a more reliable measure of head cover when the lateral point of bony condensation of the roof is chosen as the reference point rather than the edge of the bone, where these two points do not overlap. We conclude that head cover can be more accurately determined in younger children with dysplastic hips by our 'refined' $C E$ angle, than by the original method of Wiberg.
\end{abstract}

After the closed or open reduction of a congenital dislocation of the hip (CDH), it is important to know whether the hip will develop normally; femoral head coverage is the most significant factor in this prognosis. Computerised tomography (CT) can be used to assess the relationship between the femoral head and acetabulum in three dimensions, but we could find no report which quantified head cover in the transverse plane.

Of the many radiographic indicators reported, the $\mathrm{CE}$ angle of Wiberg is one of the most valuable indices of lateral coverage of the femoral head in the coronal plane (Wiberg 1953; Fredensborg 1976; Wientroub et al 1981). Wiberg's CE angle is defined by two lines from the centre of the head, one parallel with the long axis of the body and the other running through the edge of the acetabulum. The most lateral point of the acetabular roof seen on an anteroposterior (AP) radiograph is taken as the edge of the acetabulum, but, in some young patients with dysplastic hips, this point is difficult to define. In these patients, we have paid attention to the subchondral

S. Ogata, MD, Senior Registrar

H. Moriya, MD, Professor of Orthopaedics

K. Tsuchiya, MD, Lecturer

T. Akita, MD, Senior Registrar

M. Someya, MD, Senior Registrar

Department of Orthopaedic Surgery, School of Medicine, Chiba

University, 1-8-1 Inohana, Chiba-City, Chiba 280, Japan.

M. Kamegaya, MD, Pediatric Orthopaedic Surgeon

Chiba Children's Hospital, Division of Orthopaedic Surgery, 579-1

Heta-chou, Chiba-city, Chiba 280-02, Japan.

Correspondence should be sent to Dr S. Ogata.

(C) 1990 British Editorial Society of Bone and Joint Surgery $0301-620 \mathrm{X} / 90 / 2059 \$ 2.00$

J Bone Joint Surg [Br] 1990; 72-B: 190-6. bony condensation in the acetabular roof which is also seen on AP radiographs, and have located its most lateral point. We found that in some young patients with a normal CE angle who later developed poor acetabular coverage, this lateral point of bony condensation of the acetabular roof did not reach the lateral rim of the acetabular roof as seen in AP radiographs, but was situated more medially. In these patients the classical CE angle was not reliable, so we modified the method, using the lateral margin of bony condensation.

We now describe a quantitative assessment of femoral head cover in the transverse plane using CT scans; we compare these results with both the classical $\mathrm{CE}$ angle and with our 'refined' angle.

\section{PATIENTS AND METHODS}

We studied both hips in 27 children with $\mathrm{CDH}, 24$ with unilateral and three with bilateral involvement. All children had either closed or open reduction, but no surgery on the acetabulum itself. Standard radiographs and CT scans were used, one child (case 3) being examined twice within two years. Details are given in Table I. There were two boys and 25 girls with ages ranging from 2 years 10 months to 14 years 3 months (mean 6.3) at the time of investigation.

For CT scanning the children were placed supine with legs together and the knees in neutral rotation. Two scanning slices were used, one through the acetabular roof, and the other through the centre of the femoral head (Fig. 1). If both sides were not at the same level, they were scanned separately. Thus, two to four separate cuts were made in each case. 
The cut showing the acetabular roof was then superimposed on that of the femoral head, using the image of the couch as a reference. The percentage of acetabular cover of the femoral head was measured using a semi-automatic image analyser (LEITZ-ASM) and was termed the acetabular head coverage (AHC). Acetabular anteversion was also measured as shown in Figure 2.

Using the standard AP radiographs, we then compared the relative positions of the lateral end of the 'sourcil' of bony condensation and the most lateral

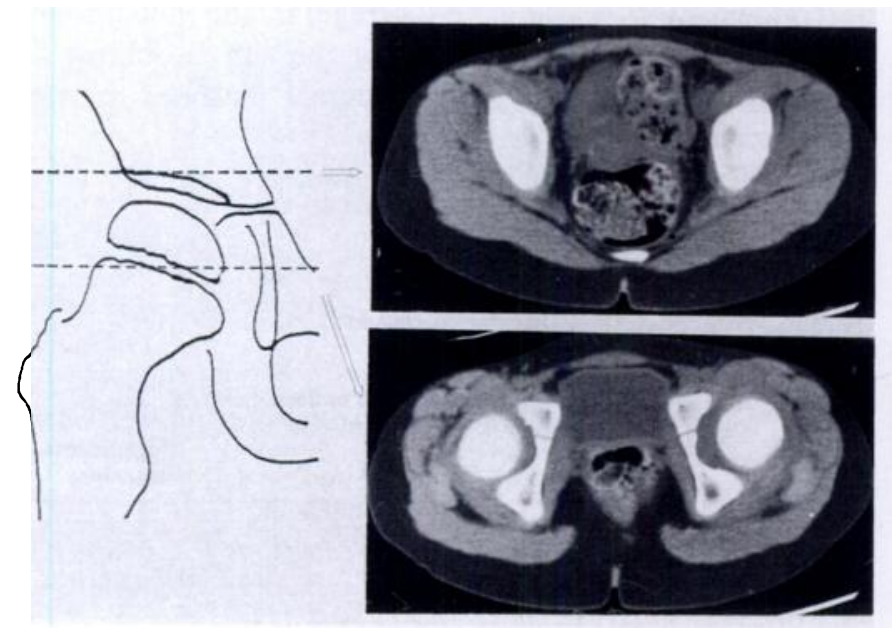

Fig. 1

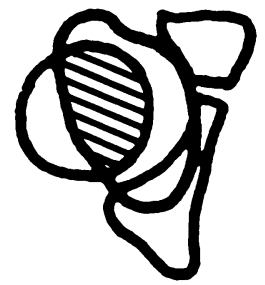

Fig. 2

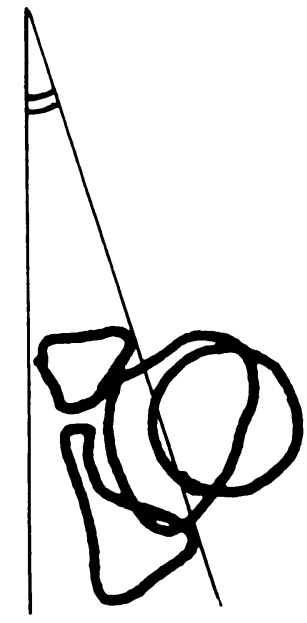

Levels of the CT slices obtained and tracings to show the method of measurement of acetabular head coverage (AHC) and of the angle of acetabular anteversion.

Table I. Details of the hips of 27 children after treatment for $\mathrm{CDH}$

\begin{tabular}{|c|c|c|c|c|c|c|c|c|c|c|c|c|c|}
\hline \multirow[b]{4}{*}{ Case } & \multirow[b]{4}{*}{ Sex } & \multirow[b]{4}{*}{ Side } & \multirow{4}{*}{$\begin{array}{l}\text { Method of } \\
\text { reduction }\end{array}$} & \multirow{4}{*}{\multicolumn{2}{|c|}{$\begin{array}{l}\text { Age at } \\
\text { scan } \\
y^{m} \mathrm{~m}\end{array}$}} & \multicolumn{4}{|c|}{$C T \operatorname{scan}$} & \multirow{3}{*}{\multicolumn{2}{|c|}{$\begin{array}{l}\text { Radiographic CE angles } \\
\text { Classical (Refined)* }\end{array}$}} & \multirow{3}{*}{\multicolumn{2}{|c|}{$\begin{array}{l}\text { Type of } \\
\text { acetabular } \\
\text { roof }\end{array}$}} \\
\hline & & & & & & \multirow{2}{*}{\multicolumn{2}{|c|}{$\begin{array}{l}\text { Acetabular } \\
\text { head } \\
\text { coverage } \\
\text { (per cent) }\end{array}$}} & \multirow{2}{*}{\multicolumn{2}{|c|}{$\begin{array}{l}\text { Acetabular } \\
\text { anteversion } \\
\text { (degrees) }\end{array}$}} & & & & \\
\hline & & & & & & & & & & & & & \\
\hline & & & & & & & & $\mathbf{R}$ & & $\mathbf{R}$ & L & & $\mathbf{L}$ \\
\hline 1 & $\mathrm{~F}$ & $\mathbf{R}$ & Closed & 5 & 8 & 29.4 & 65.8 & 19 & 18 & $-16(-27)$ & $16(6)$ & IV & III \\
\hline 2 & $\mathrm{~F}$ & L & Closed & 4 & 5 & 59.5 & 42.8 & 16 & 15 & $12(3)$ & $6(-4)$ & III & IV \\
\hline 3 & $\mathrm{~F}$ & $\mathbf{R}$ & Open & & 11 & 47.2 & 55.7 & 12 & 17 & $18(-2)$ & $24(19)$ & IV & III \\
\hline & & & & 10 & 11 & 44.6 & 81.3 & 4 & 16 & $10(-10)$ & 29 & IV & I \\
\hline 4 & $\mathbf{M}$ & $\mathbf{R}$ & Open & 4 & 7 & 0.0 & 48.5 & 15 & 11 & $10(-10)$ & 18 & IV & I \\
\hline 5 & $\mathrm{~F}$ & L & Closed & 4 & 9 & 60.7 & 60.4 & 16 & 17 & $14(8)$ & 9 & III & II \\
\hline 6 & $F$ & $\mathbf{B} \dagger$ & $\begin{array}{l}\text { Closed (R) } \\
\text { Open (L) }\end{array}$ & 4 & 3 & 59.0 & 57.2 & 24 & 21 & $9(0)$ & 7 & III & II \\
\hline 7 & $\mathrm{~F}$ & L & Closed & 4 & 0 & 84.7 & 44.1 & 7 & 14 & 13 & 0 & II & II \\
\hline 8 & $\mathrm{~F}$ & $\mathrm{~L}$ & Closed & 4 & 4 & 100.0 & 9.0 & 15 & 13 & 25 & $-10(-22)$ & II & III \\
\hline 9 & $\mathrm{~F}$ & $\mathbf{R}$ & Open & 4 & 4 & 28.0 & 72.9 & 16 & 13 & $0(-4)$ & 11 & IV & II \\
\hline 10 & $\mathrm{~F}$ & $\mathrm{~L}$ & Closed & 3 & 6 & 72.4 & 0.0 & 12 & 19 & $15(6)$ & $-10(-23)$ & III & IV \\
\hline 11 & $\mathrm{~F}$ & $\bar{L}$ & Open & 3 & 6 & 85.4 & 14.9 & 13 & 7 & 10 & $-2(-19)$ & II & III \\
\hline 12 & $\mathrm{~F}$ & B & Closed & 5 & 9 & 82.4 & 66.6 & 18 & 17 & 22 & 14 & II & II \\
\hline 13 & $\mathbf{F}$ & $\mathbf{R}$ & Closed & 10 & 2 & 21.6 & 70.8 & 23 & 19 & $-22(-26)$ & 23 & III & I \\
\hline 14 & $\mathrm{~F}$ & B & Closed & 7 & 4 & 62.7 & 57.2 & 14 & 17 & $6(-13)$ & 7 & III & I \\
\hline 15 & M & $\mathrm{L}$ & Closed & 4 & 10 & 86.2 & 59.0 & -4 & 14 & $20(11)$ & $20(-2)$ & III & IV \\
\hline 16 & $\mathrm{~F}$ & $\mathrm{~L}$ & Closed & 12 & 6 & 88.3 & 0.0 & 20 & 12 & 20 & $-132(-136)$ & I & IV \\
\hline 17 & $\mathrm{~F}$ & $\mathbf{R}$ & Closed & & 10 & 30.6 & 52.4 & 26 & 24 & -18 & 0 & II & Il \\
\hline 18 & $\mathrm{~F}$ & $\ddot{\mathrm{L}}$ & Closed & 14 & 3 & 81.3 & 74.8 & 19 & 18 & 22 & 22 & I & II \\
\hline 19 & $\mathrm{~F}$ & $\mathrm{~L}$ & Open & 8 & 3 & 70.9 & 35.8 & 18 & 15 & 5 & -25 & I & II \\
\hline 20 & $\mathrm{~F}$ & $\mathrm{~L}$ & Closed & 4 & & 72.3 & 16.1 & 20 & 11 & 12 & $-10(-37)$ & II & IV \\
\hline 21 & $\mathrm{~F}$ & $\overrightarrow{\mathrm{L}}$ & Closed & 5 & 6 & 78.1 & 7.4 & 15 & 21 & 13 & $-66(-70)$ & II & IV \\
\hline 22 & $F$ & L & Closed & 11 & 5 & 77.9 & 23.2 & 28 & 22 & 25 & $-13(-16)$ & I & IV \\
\hline 23 & $\mathrm{~F}$ & $\mathrm{~L}$ & Closed & 6 & 8 & 72.7 & 59.3 & 9 & 12 & 14 & 15 & I & II \\
\hline 24 & $\mathrm{~F}$ & $\mathrm{~L}$ & Closed & 3 & 11 & 58.3 & 32.1 & 15 & 15 & $15(4)$ & -7 & III & II \\
\hline 25 & $\mathrm{~F}$ & $\mathbf{R}$ & Closed & 5 & 4 & 46.9 & 53.7 & 20 & 16 & $4(-6)$ & $12(5)$ & III & III \\
\hline 26 & $\mathrm{~F}$ & $\mathbf{R}$ & Closed & 6 & & 49.8 & 60.3 & 17 & 17 & $0(-11)$ & 16 (11) & IV & III \\
\hline 27 & $\mathrm{~F}$ & R & Closed & 4 & 11 & 39.0 & 79.9 & 15 & 17 & $15(3)$ & 20 & IV & II \\
\hline
\end{tabular}

* refined CE angle measured only in type III and IV acetabula † bilateral 
projection of the acetabular roof with the outline of the acetabular rim seen on the CT scans, in an attempt to classify the various shapes of acetabular roof. The CE angle of Wiberg was then measured on standard pelvic radiographs. Where, in young children, the lateral point of the bony condensation differed from the most lateral point of the roof, we measured from both points. Both the classical and the 'refined' $\mathrm{CE}$ angles were recorded.

Statistical analysis was performed by Student's- $t$ method, and linear regression analysis was used to estimate the relationship between acetabular head coverage and the $\mathrm{CE}$ angles.

\section{RESULTS}

Detailed data are given in Table I. In the 24 unilateral cases, we found a significant difference between acetabular head coverage (AHC) on the affected and the unaffected sides ( $p<0.01)$, but there was no significant difference in acetabular anteversion between these sides (Table II).

Comparison of the position of the two radiographic reference points with the outline of the acetabular rim on the CT scan made it possible to classify the shape of the acetabular roof into one of four types (Fig. 3):

Type $I$ - bony condensation in the acetabular roof overlaps the most lateral point of the roof: an acetabular beak is clearly delineated. In this type, the CT scan showed a round acetabular rim with its most lateral point halfway between its anterior and posterior ends.

Type II - the bony condensation overlaps the most lateral point of the acetabular roof but no definite acetabular beak is seen. On the CT scan, the outline of the acetabular rim is straight, lying in the sagittal plane.

Type III - there is a small interval between the lateral edge of bony condensation and the most lateral point of acetabular roof, and the bony condensation is uniform, well defined and smooth. On the CT scan, the edge of the acetabular rim is oblique, and it is narrower posteriorly.

Type IV - there is a considerable distance between the most lateral point of bony condensation and the most lateral point of the acetabular roof, and the bony condensation is ill-defined, irregular and not uniform. On the CT scan, the outline of the rim is oblique and irregular, often showing a defect halfway between anterior and posterior margins.

The number of hips and the average age of the

Table II. Results in 56 hips

\begin{tabular}{|c|c|c|c|}
\hline & Affected side $(\mathrm{n}=31)$ & $\begin{array}{l}\text { Unaffected side } \\
(\mathbf{n}=\mathbf{2 5})\end{array}$ & \\
\hline & Mean \pm s.d. & Mean \pm s.d. & difference \\
\hline $\begin{array}{l}\text { Acetabular head } \\
\text { cover (per cent) }\end{array}$ & $38.8 \pm 22.4$ & $71.6 \pm 12.8$ & $\mathrm{p}<0.01$ \\
\hline $\begin{array}{l}\text { Acetabular } \\
\text { anteversion } \\
\text { (degrees) }\end{array}$ & $16.2 \pm 4.6$ & $15.5 \pm 5.9$ & NS \\
\hline
\end{tabular}

Table III. Type of acetabular roof (see text) related to the average age of the patients

\begin{tabular}{lllll}
\hline & \multicolumn{4}{l}{ Type of acetabular roof } \\
\cline { 2 - 5 } & I & II & III & IV \\
\hline Number of hips & 9 & 18 & 15 & 14 \\
$\begin{array}{l}\text { Average age } \\
\text { Mean } \pm \text { s.d.) }\end{array}$ & $9.6 \pm 2.9^{*}$ & $5.2 \pm 2.5$ & $5.5 \pm 1.9$ & $6.5 \pm 2.9$ \\
\hline
\end{tabular}

* difference from others significant at $\mathrm{p}<0.05$
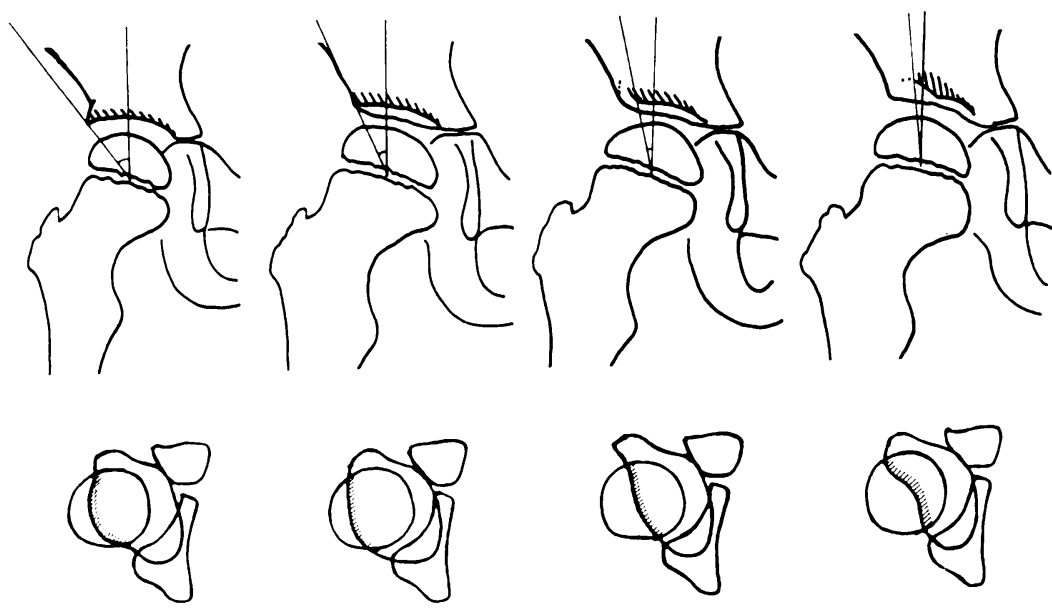

I
II

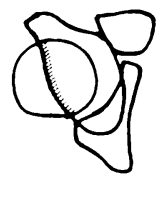

III

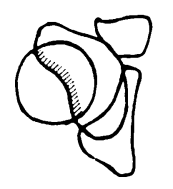

IV
Classification of the acetabular roof, measurement of the classical CE angle in types I and II, and of the 'refined' angle in types III and IV.

Fig. 3 
patients in these four groups are given in Table III. All but one of type I acetabula were seen on the unaffected side, and all of the type IV acetabula were seen on the affected side. The average age of children with type I was significantly higher than those of the other types $(\mathrm{p}<0.05)$. The acetabular head coverage (AHC) of type

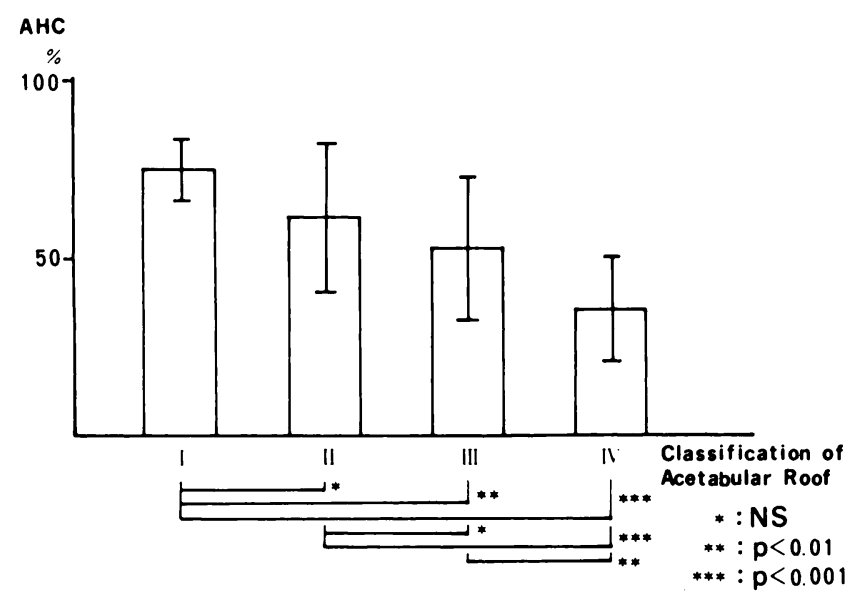

Fig. 4

Bar graph showing acetabular head coverage (AHC) in each type of acetabulum, and the significance of differences.
IV was significantly lower than that in the other types (Fig. 4). In types III and IV the 'refined' CE angle was consistently lower. The difference between the classical and refined CE angles was larger in type IV (mean $12.9^{\circ}$ ) than in type III (mean $9.4^{\circ}$ ), but the difference was not significant.

The relationship between the acetabular cover measured by $C T$ scan and the classical $C E$ angle measured radiographically was studied by regression analysis. The slopes of the regression lines calculated separately for affected and unaffected hips were fairly different (Fig. 5), but the slope of the regression lines for types I and II together and for types III and IV together (Fig. 6) were almost parallel with that for types III and IV below the other. This shows that, in types III and IV, the classical $\mathrm{CE}$ angle overestimates the head coverage.

In contrast, the relationship between acetabular cover and the refined CE angle in types III and IV shown in Figure 7, where the regression lines almost coincide, reveals a very high correlation.

\section{ILLUSTRATIVE CASE REPORTS}

Case 3. This girl had an open reduction of congenital dislocation of the right hip. At 8 years 11 months the classical CE angle was $18^{\circ}$ (left side $24^{\circ}$ ) an apparently satisfactory cover. The refined $\mathrm{CE}$ angle, however,

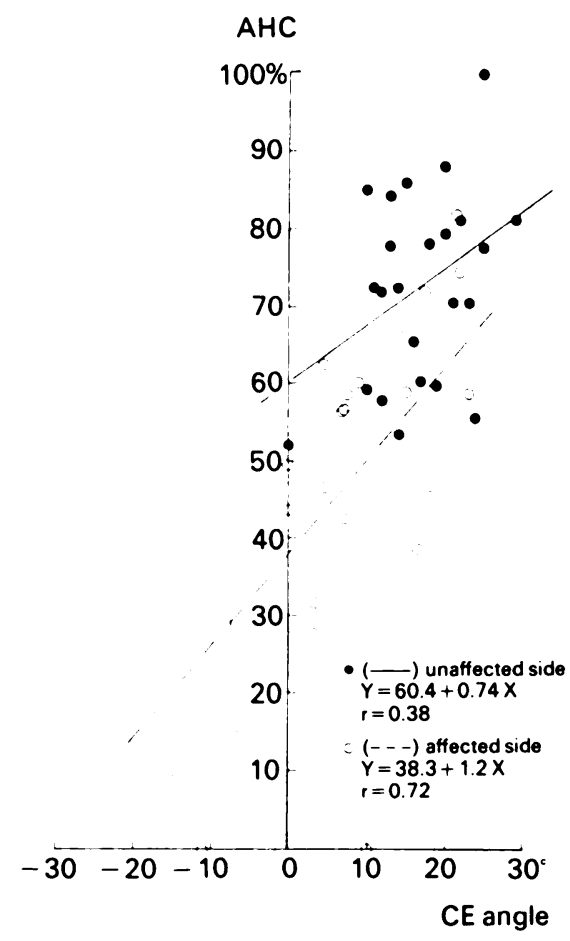

Fig. 5

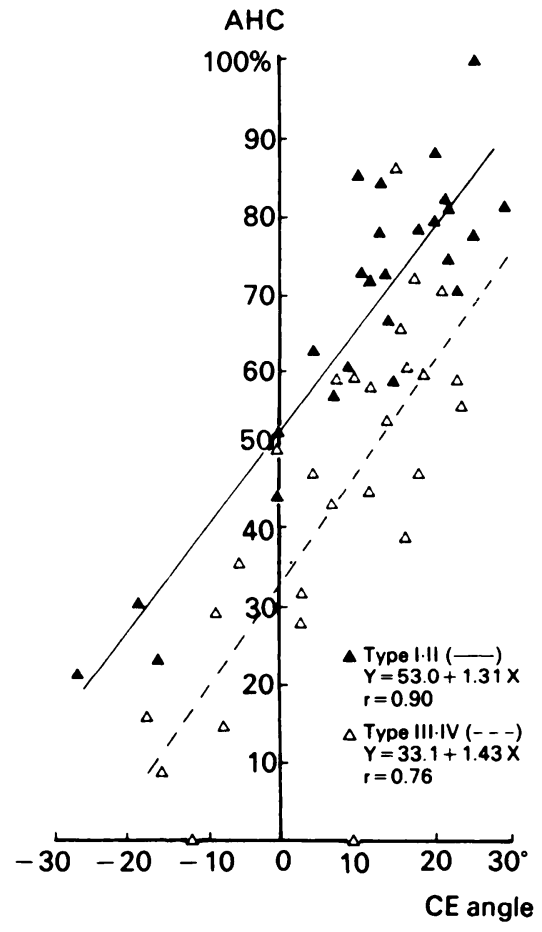

Fig. 6

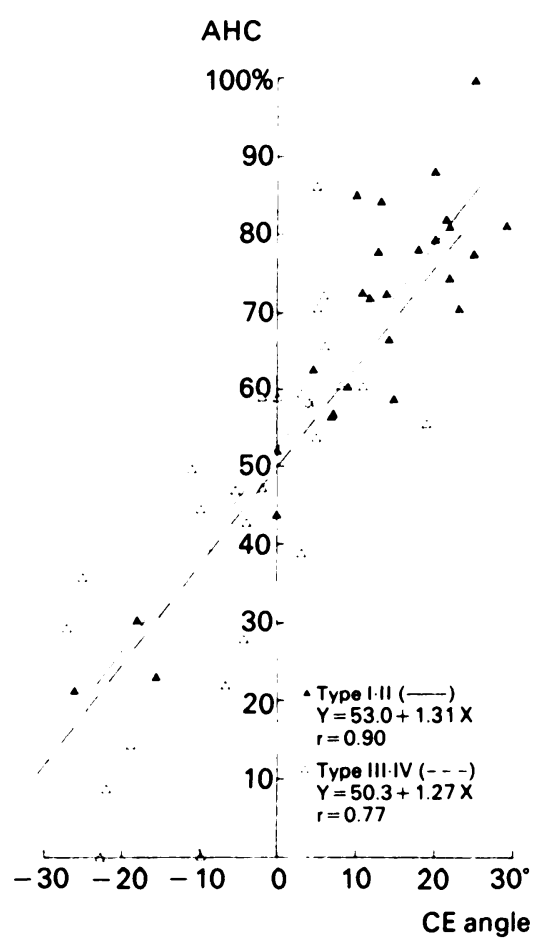

Fig. 7

Figure 5 - Relationship between the classical CE angle and acetabular head coverage. Regression lines calculated separately for unaffected and affected sides. Figure 6 - Regression lines calculated separately for types I and II as against types III and IV. Figure 7 - Relationship between the 'refined' CE angle and acetabular head coverage. The regression line for types III and IV has been recalculated for the new angles. 


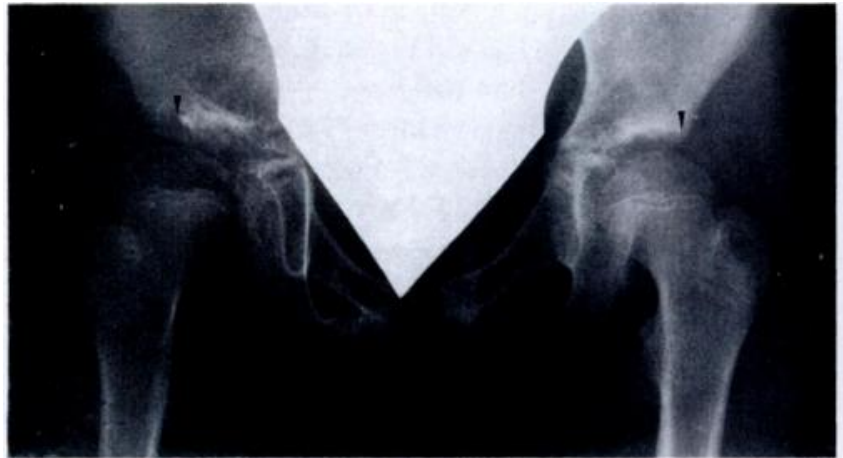

Fig. 8

Case 3. Figure 8 - Radiograph of an 8-year-old girl. In the right hip the contour of the bony condensation is ill-defined and there is sume distance between its most lateral point (arrow head) and the edge of the apparent acetabular roof. Figure 9 - The CT scan of the acetabular roof shows irregularity and a defect in the osseous acetabular rim on the right. Figure 10 -Acetabular head coverage was $47.2 \%$ on the right and $55.7 \%$ on the left.

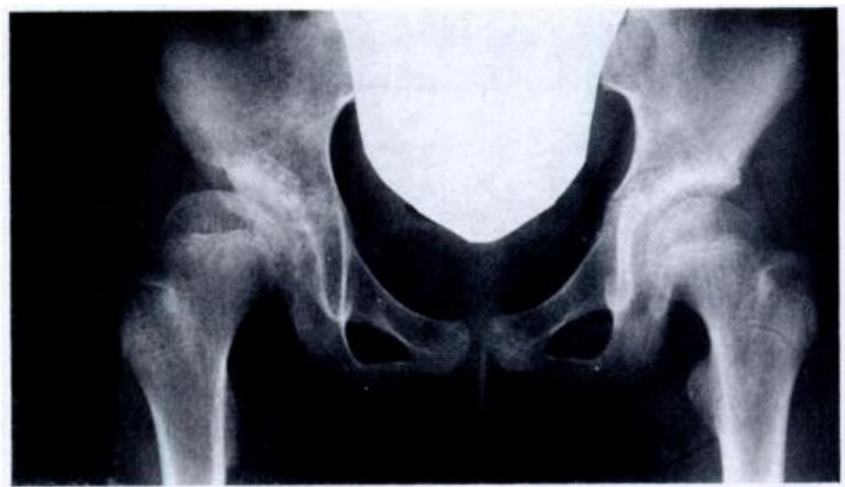

Fig. 11

Figure 11 - Radiograph of same patient as Figs 8 to 10 (case 3) two years later. The right acetabulum is shallow. Figure 12 The CT scan shows persistence of the defect in the acetabular rim of the right hip. especially when compared with the well-formed left acetabular roof Figure $13 \ldots$ Acetabular head coverage was $44.6 \%$ on the right and $81.3 \%$ on the left.

measured only $-2^{\circ}$ (left side $19^{\circ}$ ) (Fig. 8) and the C'T scan showed an irregular acetabular edge (Fig. 9). Acetabular cover was $47.2 \%$ on the affected side as against $55.7 \%$ on the other (Fig. 10). The right hip was classified as type IV.

Two years later, dysplasia of the right hip was apparent (Fig. 11); a repeat CT scan showed an osseous defect of the acetabular edge on the affected side in contrast to the normal edge on the unaffected side (Fig.

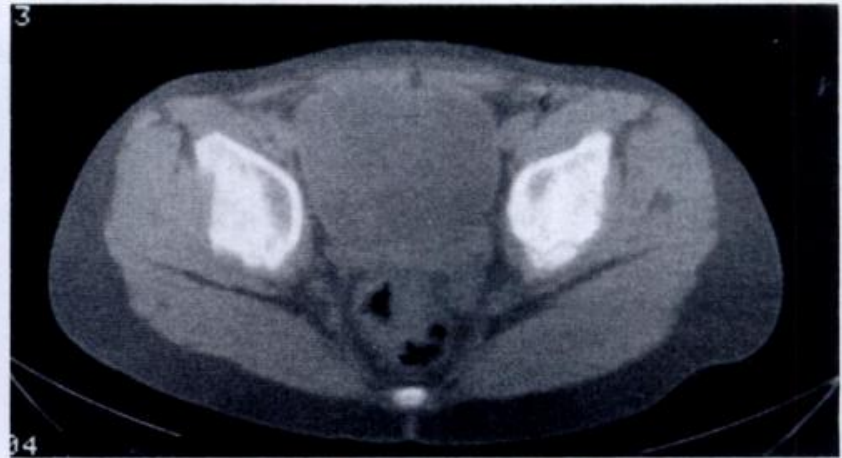

Fig. 9
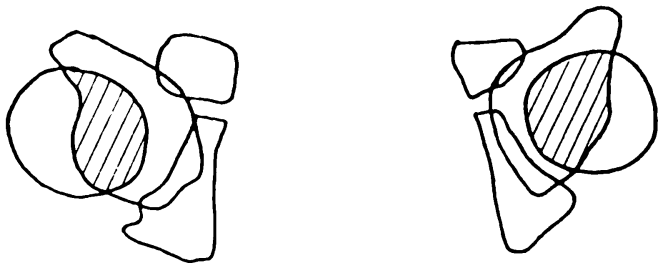

Fig. 10

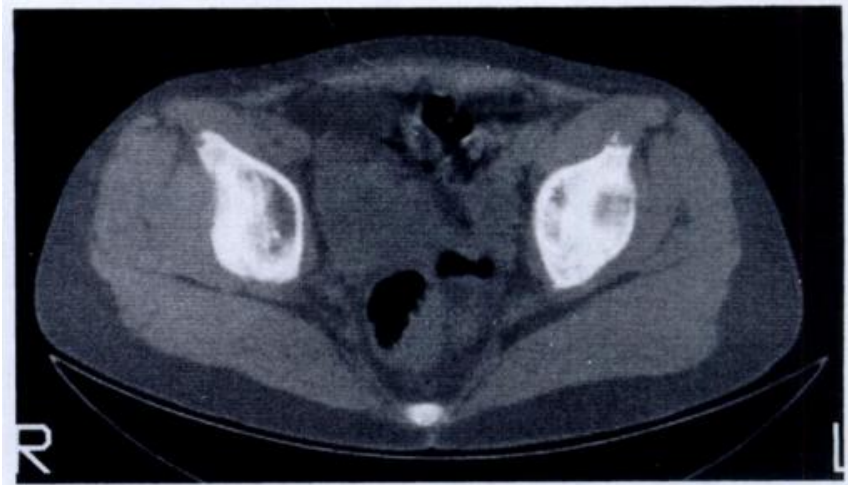

Fig. 12
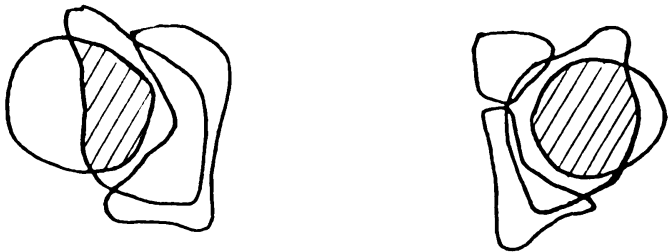

Fig. 13

12). Acetabular cover was $44.6 \%$ on the affected side and $81.3 \%$ for the unaffected side (Fig. 13).

Case 15. This boy had had closed reduction and a cast for congenital dislocation of the left hip. At 4 years 10 months, standard AP radiographs showed an acceptable reduction, but there was a considerable distance between the zone of bony condensation and the lateral rim of the acetabulum. The refined $\mathrm{CE}$ angle was $-2^{\circ}$ (Fig. 14). A CT scan showed an osseous defect in the lateral edge of 
the acetabulum (Fig. 15). The acetabular cover was $59.0 \%$ on the left and $86.2 \%$ on the right (Fig. 16). This hip was classified as type IV: further treatment will be necessary.

\section{DISCUSSION}

The use of computerised tomography in paediatric hip problems has been reported (Lasda et al 1978; Peterson et al 1981; Visser, Jonkers and Hillen 1982) but mainly for the detection of dislocation or subluxation when a cast obscures details on standard radiographs, or when measurements of femoral torsion and acetabular anteversion are needed. We have used it to make quantitative assessments of femoral head coverage in the transverse plane.

Wiberg (1939) originally described the CE angle in adults, and Severin (1941) applied it to children over six years of age. Massie and Howorth (1950) also used it in children and, later, Wiberg (1953) studied the development of the acetabular roof and applied his index to children over four years of age, but there has been little discussion on the reference point to be used. We found this easy where the lateral point of bony condensation of the acetabular roof overlies the most lateral point of the acetabular roof (our types I and II). It is more difficult when the points are not superimposed (our types III and IV).

The type I acetabulum, with a lateral beak, is seen in older children. In type II the osseous rim lies in a sagittal plane (as seen in the CT image) so that its

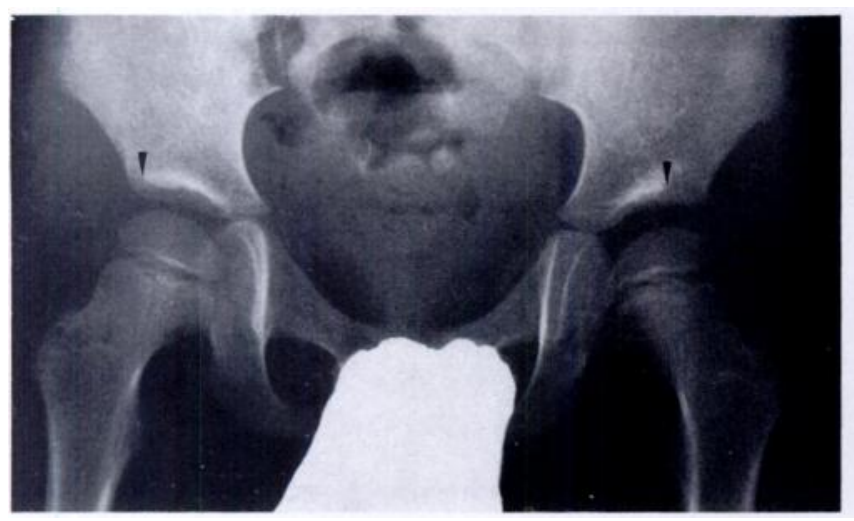

Fig. 14 anterior, middle and posterior edges are superimposed on an AP radiograph and easily localised. In type III acetabula, by contrast, the distance between the lateral point of the bony condensation and the lateral edge of roof is due to the oblique orientation of the acetabular rim. In type IV acetabula, the irregularity and defects in the bony rim show up as a considerable distance between the two points. In types III and IV acetabula, the most lateral point of the acetabular roof on AP radiographs is actually anterior and lateral to the most superior part of the acetabulum (see Fig. 3). Measurement of the CE angle from the most lateral classical reference point may seriously overestimate the femoral head cover.

It is therefore imperative to distinguish between the two points of reference, and use the refined CE angle in types III or IV acetabula. In our case 3, a type III acetabulum on the left developed into type I in two years, but the type IV acetabulum on the right failed to develop normally. It is well known that subchondral bony condensation in the acetabulum outlines the area of high compressive stresses even in young children (Tachdjian 1982), but it seems that the difference in contour and consistency of the bony condensation between our types III and IV may explain the difference in the potential of acetabular development. In a type IV acetabulum, with an appreciable distance between the apparent lateral rim and the edge of bony condensation, careful follow-up should include CT examination to establish the shape of the defect. This will allow proper treatment to prevent later subluxation and secondary osteoarthritis. Where the classification into type III or IV is doubtful, CT

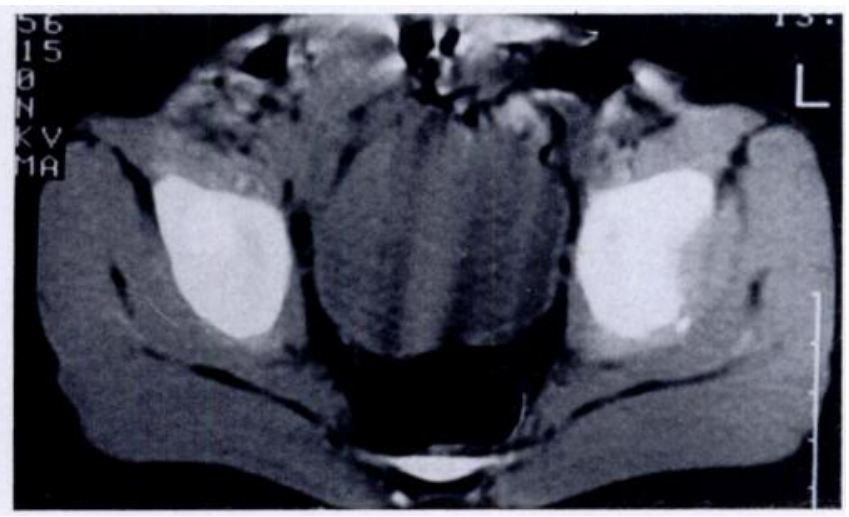

Fig. 15

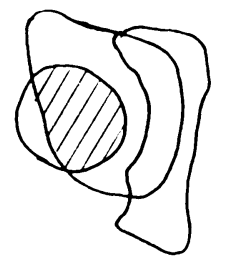

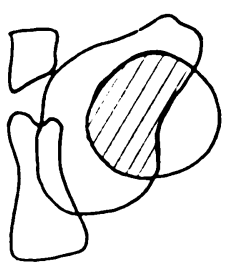

Fig. 16 
examination may also be helpful. In all other young children with $\mathrm{CDH}$, the use of the refined $\mathrm{CE}$ angle, measured to the lateral edge of the bony condensation, will be sufficient to determine the femoral head coverage; routine $\mathrm{CT}$ scans are not necessary in these cases.

The authors would like to thank Dr H. K. Uhthoff of the University of Ottawa for help in the preparation of this manuscript.

No benefits in any form have been received or will be received from a commercial party related directly or indirectly to the subject of this article.

\section{REFERENCES}

Fredensborg N. The CE angle of normal hips. Acta Orthop Scand 1976; 47:403-5.

Lasda NA, Levinsohn EM, Yuan HA, Bunnell WP. Computerized tomography in disorders of the hip. J Bone Joint Surg [Am] 1978; 60-A :1099-102.

Massie WK, Howorth MB. Congenital dislocation of the hip: Part 1. Method of grading results. J Bone Joint Surg [Am] 1950; 32-A 519-31.
Peterson HA, Klassen RA, McLeod RA, Hofiman AD. The use of computerised tomography in dislocation of the hip and femoral neck anteversion in children. $J$ Bone Joint Surg $[\mathrm{Br}] 1981$; 63B:198-208.

Severin E. Contribution to knowledge of congenital dislocation of hip joint: late results of closed reduction and arthrographic studies of recent cases. Acta Chir Scand 1941 [Suppl 63]; 84; 1-142.

Tachdjian MO. Treatment of hip dysplasia in the older child and adolescent: factors in decision making. In: Tachdjian MO, ed. Congenital dislocation of the hip. New York, etc: Churchill Livingstone, 1982; 625-46.

Visser JD, Jonkers A, Hillen B. Hip joint measurements with computerized tomography. J Pediatr Orthop 1982; 2:143-6.

Wiberg G. Studies on dysplastic acetabula and congenital subluxation of the hip joint: with special reference to the complication of osteoarthritis. Acta Chir Scand 1939; 83:Suppl 58.

Wiberg G. Shelf operation in congenital dysplasia of the acetabulum and in subluxation and dislocation of the hip. $J$ Bone Joint Surg [Am] 1953; 35-A :65-80.

Wientroub S, Tardiman R, Green I, Salama R, Weissman SL. The development of the normal infantile hip as expressed by radiological measurements. Int Orthop 1981; 4:239-41. 